\title{
A Conceptual Assessment Framework for K-12 Computer Science Rubric Design
}

\author{
Bita Akram ${ }^{1}$, Wookhee Min ${ }^{1}$, Eric Wiebe ${ }^{1}$, Anam Navied ${ }^{1}$, \\ Bradford Mott ${ }^{1}$, Kristy Elizabeth Boyer ${ }^{2}$, James Lester ${ }^{1}$ \\ ${ }^{1}$ North Carolina State University, Raleigh, North Carolina \\ ${ }^{2}$ University of Florida, Gainesville, Florida \\ \{bakram,wmin, wiebe, anavied, bwmott, lester\}@ncsu.edu \\ keboyer@ufl.edu
}

\begin{abstract}
The lack of effective guidelines for assessing students' computer science (CS) competencies is creating significant demand by $\mathrm{K}-12$ teachers for CS assessments to evaluate students' learning. We propose a conceptual assessment framework that guides teachers through designing appropriate assessments for computer science (CS) activities in their classrooms. The framework addresses the critical problem of incorporating CS into K-12 curricula without corresponding assessments. We illustrate its use with the design of a rubric for a bubble sort algorithm situated in a game-based learning environment for middle-grade students. We also apply a preliminary and a revised version of this assessment on two datasets collected from students' interactions with the learning environment. We found consistency among results identified through applying the preliminary and the revised rubric. The results reveal distinctive patterns in students' approaches to CS problem solving and coherency with respect to different aspects of the rubric.
\end{abstract}

\section{KEYWORDS}

CS Assessment; Evidence Centered Design; K-12 CS Instruction

\section{INTRODUCTION}

Recent years have seen a growing body of curriculum developed for teaching programming and computer science to $\mathrm{K}-12$ students. However, there is not much emphasis on how to effectively assess students' understanding of the embedded CS concepts [1]. This is particularly challenging for non-CS teachers. In this poster, we present a conceptual assessment framework that guides teachers through designing robust rubrics for CS assignments. Our framework adopts an evidence-centered assessment design approach [2] and uses a hypothesis-driven assessment framework proposed by Grover et al. [1]. Evidencecentered assessment design has been used successfully to assess students' skills and knowledge constructs in a broad range of game-based learning environments and simulations [2, 3].

Permission to make digital or hard copies of part or all of this work for personal or classroom use is granted without fee provided that copies are not made or distributed for profit or commercial advantage and that copies bear this notice and the full citation on the first page. Copyrights for third-party components of this work must be honored. For all other uses, contact the Owner/Author. SIGCSE '20, March 11-14, 2020, Portland, OR, USA.

(C) 2020 Copyright is held by the owner/author(s).

ACM ISBN 978-1-4503-6793-6/20/03.

https://doi.org/10.1145/3328778.3372643

\section{METHODS AND RESULTS}

We utilize this framework to design a rubric for a bubble-sort challenge situated within a CS game-based learning environment. Following the presentation of the assessment framework, we identify CS concepts that are required to solve the bubble sort challenge. We then extract and evaluate features and patterns of interaction that are representative of students' competencies in the CS concepts identified. A three-dimensional rubric is then designed to assess students in accordance with their competency in essential CS concepts, their dynamic testing and refining strategies, and their problem-solving efficiency. We revise and apply this rubric on data collected from a total of 91 students over two studies. The primary finding of analyses from these studies is that students' knowledge of essential CS concepts is the foundation for their ability to develop effective algorithms.

\section{CONTRIBUTIONS AND FUTURE WORK}

This work provides an important first step toward a rigorous approach for designing assessments for CS activities. An important direction for future work is to evaluate its effectiveness by conducting interviews with teachers and comparing teacher-designed with expert-designed assessments.

\section{ACKNOWLEDGMENTS}

This research was supported by National Science Foundation (NFS) Grant DRL-1640141. Any opinions, findings, and conclusions expressed in this material are those of the authors and do not necessarily reflect the views of the NSF.

\section{REFERENCES}

[1] S. Grover, S. Basu, M. Bienkowski, M. Eagle, N. Diana, and J. Stamper. 2017. A framework for using hypothesis-driven approaches to support data-driven learning analytics in measuring computational thinking in block-based programming environments. ACM Transactions on Computing Education, $17(3): 1-25$.

[2] R. Mislevy, and G. Haertel. 2007. Implications of Evidence-Centered Design for Educational Testing. Educational Measurement: Issues and Practice, 25(4):6-20.

[3] B. Akram, W. Min, E. Wiebe, B. Mott, K.E. Boyer, and J. Lester. 2018. Improving Stealth Assessment in Game-Based Learning with LSTM-Based Analytics. In Proceedings of the Eleventh International Conference on Educational Data Mining, pp. 208-218. 